\title{
THE EFFECT OF THE ALUMINIUM ALLOY SURFACE ROUGHNESS ON THE RESTITUTION COEFFICIENT
}

\author{
Stanisław Bławucki', Kazimierz Zaleski' \\ 1 Faculty of Mechanical Engineering, Lublin University of Technology, 36 Nadbystrzycka Str., 20-618 Lublin, \\ Poland, e-mail: s.blawucki@pollub.pl; k.zaleski@pollub.pl
}

Received: 2015.07.19

Accepted: 2015.08.05 Published: 2015.09.01

\begin{abstract}
The paper presents the results of research on the effect of the surface roughness of aluminum alloy on its coefficient of restitution. It describes the current method of finishing the workpiece surface layer after cutting and innovative measuring device which was used in the research. The material used in the research was aluminium alloy EN AW 7075. The paper also presents a relationship between the coefficient of restitution and surface roughness of the milled samples as well as impressions left by bead in function of velocity and a sample surface roughness.
\end{abstract}

Keywords: coefficient of restitution, shot peening, surface roughness, aluminium alloy treatment.

\section{INTRODUCTION}

Removal machining of machine parts is widely used for changing the geometry of the workpiece and the properties of its surface layer. The important surface layer parameters include: surface roughness, microhardness, residual stress and surface defects like cracks and corrosive pitting. Final dimension of workpiece and its corrosion resistance depend on surface roughness [1]. In the production environment, the roughness is controlled by the selection of process parameters, such as cutting velocity, depth of cut and velocity of feed motion. Roughing usually allows the maximization of process efficiency, but this effect is connected with the increase of the surface roughness. On the surface of the workpiece there are characteristic marks, which represent the shape of the geometry of the cutting tool edge (Fig. 1a). They are the outlines of the arc left by the edges of the mill's working part. Parameter $\mathrm{Rz}$ value is dependent on the tool edge entering angle, nose radius and feed per tooth.

Grinding leads to surface roughness reduction and, at the same time, ensures more homogenous stress condition in the surface layer of the work- piece. Currently, grinding operations are mostly eliminated because of low performance and unfavorable work conditions for a machine operator.

Burnishing and shot peening are a modern form of finishing treatment of the workpiece surface layer manufactured with the use of the removal machining technique. Burnished parts should have a low level of surface roughness. That condition is necessary to gain homogenous intensity of burnishing, that is to say, uniform stress state and strain $[2,3]$. The research shows that there is some possibility of creating ascent plastic deformation of the surface of the workpiece (shaft type) with the use of roller burnishing $[4,5]$. Using a special tool with appropriate geometry and selecting its correct treatment parameters is an important condition.

In the case of workpieces different from axially symmetrical, vibrating and streaming shot peening is used. The restriction on vibrating shot peening is the overall dimension and mass of a workpiece. The problem with streaming shot peening appears at the beginning of the process - when machining parameters are being selected: air stream pressure, diameter and material of beads, distance from workpiece and time of exposition [6]. Wrong selection of process parameters 

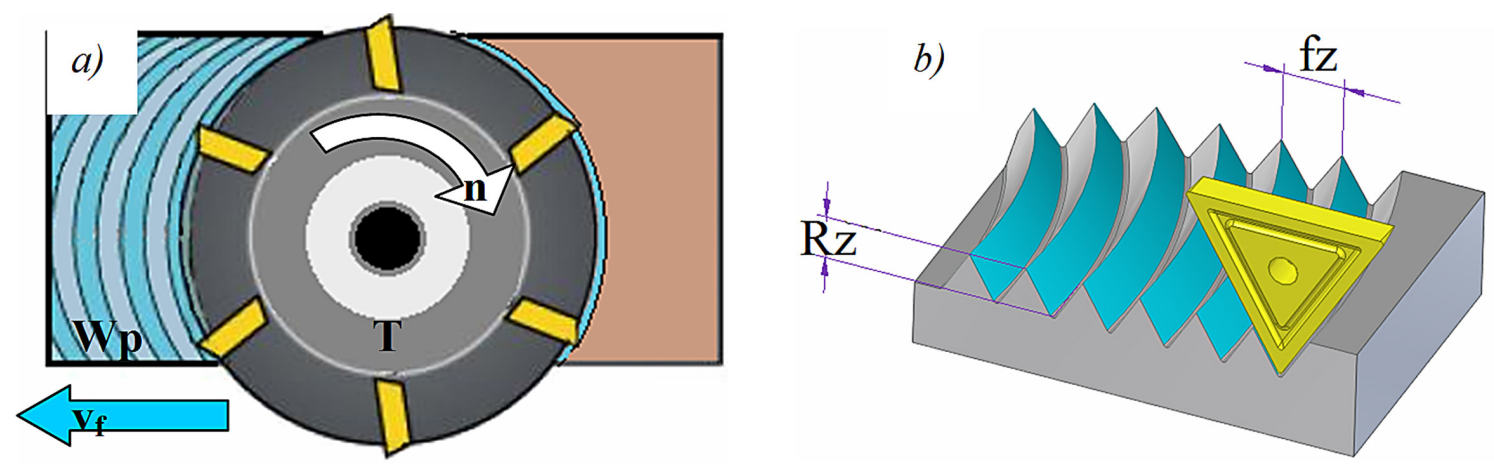

Fig. 1. Characteristics of cutting on the example of face milling: a) kinematics of treatment: Wp - workpiece, $\mathrm{T}$ - cutting tool, $\mathrm{v}_{\mathrm{f}}$ - feed velocity, $\mathrm{n}$ - rotation speed, $\mathrm{b}$ ) geometric structure of part of surface machined by the tool with small radius of corner rounding

can lead to the destruction of the surface layer or lack of the intended effect of the process.

During the finishing treatment through shot peening, complicated processes in the zone of deformation (Fig. 2a) take place. The treatment effect is not observed for hard materials. All of kinetic energy of beads before impact turns into the kinetic energy of rebound. In this case, the coefficient of restitution e (which describes energy recovery) is approximately equal to one [7]. For elastic-plastic and plastic materials, the kinetic energy of beads turns into plastic deformation and deformation of strengthening. The above-mentioned processes are accompanied by intensive heat release during sinking as a result of beads friction on the workpiece surface. This phenomenon is accompanied by slight mechanical vibrations which are damped by adhesion forces between beads and workpiece. For plastic materials, all of the kinetic energy turns into permanent deformation, so the coefficient of restitution e is equal to zero [8].

Metals and metal alloys have the characteristics of elastic-plastic materials. They present favorable hardness and compactness of crystal structure while their plasticity is retained. The determination of Young's and Kirchhoff's modules for elastic-plastic material requires precise laboratory research with adequate sample preparation. Besides, the transfer from research results to production ground often causes many problems and is time-consuming.

The alternative to advanced research on material treated by deformation is to determine the coefficient of restitution of material at the stage of initial treatment tests in the production conditions. It is enough to measure the incidence of reflection velocity of bead to find if a workpiece is vulnerable to finishing treatment. It is assumed that the material of bead is non-deformable. The previous research on polished samples of titanium alloy WT3-1 proves that the coefficient of restitution is not dependent on the diameter of bead, but is dependent on the velocity of bead hitting [10].

The purpose of this study is to evaluate the influence of surface roughness of milled aluminum alloy on the coefficient of restitution.

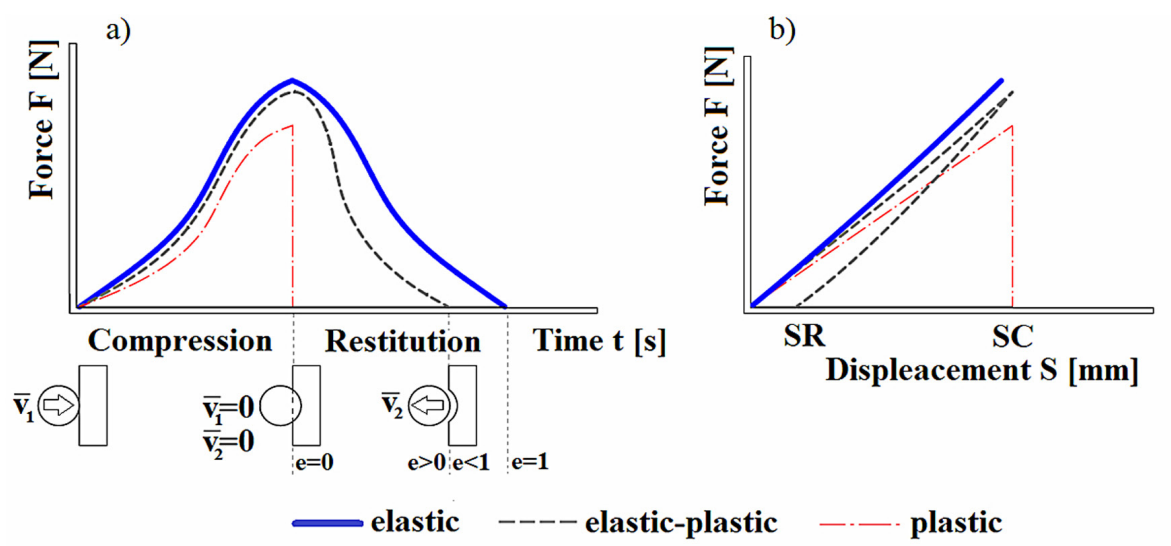

Fig. 2. Scheme of interaction between bead and workpiece: a) bead force on function of time: $v_{1}-$ velocity of bead before hitting, $\mathrm{v}_{2}$ - velocity of bead after hitting, e - coefficient of restitution, b) compressive force in function of its displacement into material: SR - limit of restitution, SC - limit of plastic deformation [9] 


\section{METHODS}

During research, milled samples $60 \times 60 \times 10 \mathrm{~mm}$ (aluminum alloy EN AW 7075) were used. Milling was performed on a vertical machining centre FV580a (Fig. 3). Feed value $\left(f_{z}\right)$ fluctuated between $0.01-0.55 \mathrm{~mm}$ per tooth with a step of 0.10 $\mathrm{mm}$ per tooth. Cutting speed $\left(\mathrm{v}_{\mathrm{c}}\right)$ was constant and equal to $395 \mathrm{~m} / \mathrm{min}$ and depth of cut $\mathrm{a}_{\mathrm{p}}$ was equal

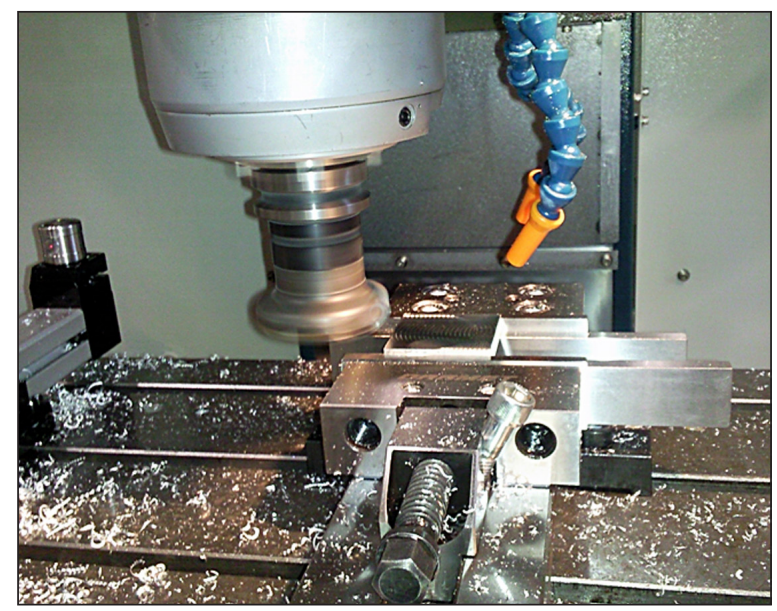

Fig. 3. Milling of workpiece surface

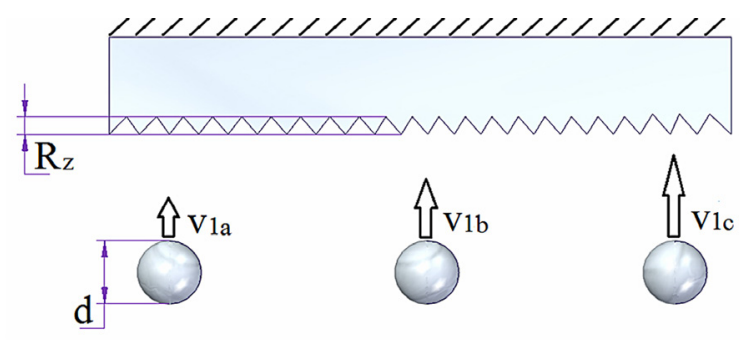

Fig. 4. Experiment parameters: Rz - roughness height, $\mathrm{d}$ - bead diameter, $\mathrm{v}_{\mathrm{la}}, \mathrm{v}_{1 \mathrm{~b}}, \mathrm{v}_{\mathrm{lc}}$ - bead initial velocity to $0.50 \mathrm{~mm}$. The face mill with a diameter of 63 $\mathrm{mm}$ with replaceable cutting edges was used.

The research methodology involved determining the influence of surface roughness and the shot medium velocity on the coefficient of restitution and diameter of impression after bead impact (Fig. 4). All the preliminary examination determined the scope of the test factors value. Test factors involved: one size of bead d, eight heights of the roughness $\mathrm{Rz}$ of the test samples, and three values of pressure at which the bead acquired its initial velocity $\mathrm{v}_{1 \mathrm{a}}, \mathrm{v}_{1 \mathrm{~b}}, \mathrm{v}_{1 \mathrm{c}}$.

The constant parameters of the experiment included: type of workpiece material - EN AW 7075 aluminium alloy, diameter of bead $d=5.50$ $\mathrm{mm}$ and bead impact path set to $260 \mathrm{~mm}$. With a constant bead diameter its throw pressure was changed within the range from 0.3 to $0.5 \mathrm{MPa}$, which allowed for achieving the velocity of $\mathrm{v}_{1 \mathrm{a}}$ $=5 \mathrm{~m} / \mathrm{s}, \mathrm{v}_{1 \mathrm{~b}}=7 \mathrm{~m} / \mathrm{s}, \mathrm{v}_{1 \mathrm{c}}=9 \mathrm{~m} / \mathrm{s}$. The roughness of the surface was controlled by alternating feed per tooth. Each measurement was repeated fifteen times, and extreme values were rejected.

The measurements were performed on the test stand for determining the coefficient of restitution (Fig. 5). It consist of a measuring system (2), a compressor (1) and an electronic control system (5). The components are fixed to the base (2) of the stand. Inside the rack (13) there is a square section hollow tunnel and a decompression slot. The upper part of the rack is equipped with two sensors (12) for measuring the time of bead travel between the sensors. In the upper part of the test stand there is a stage with a bumper (10). The bumper ensures the workpiece (11) is

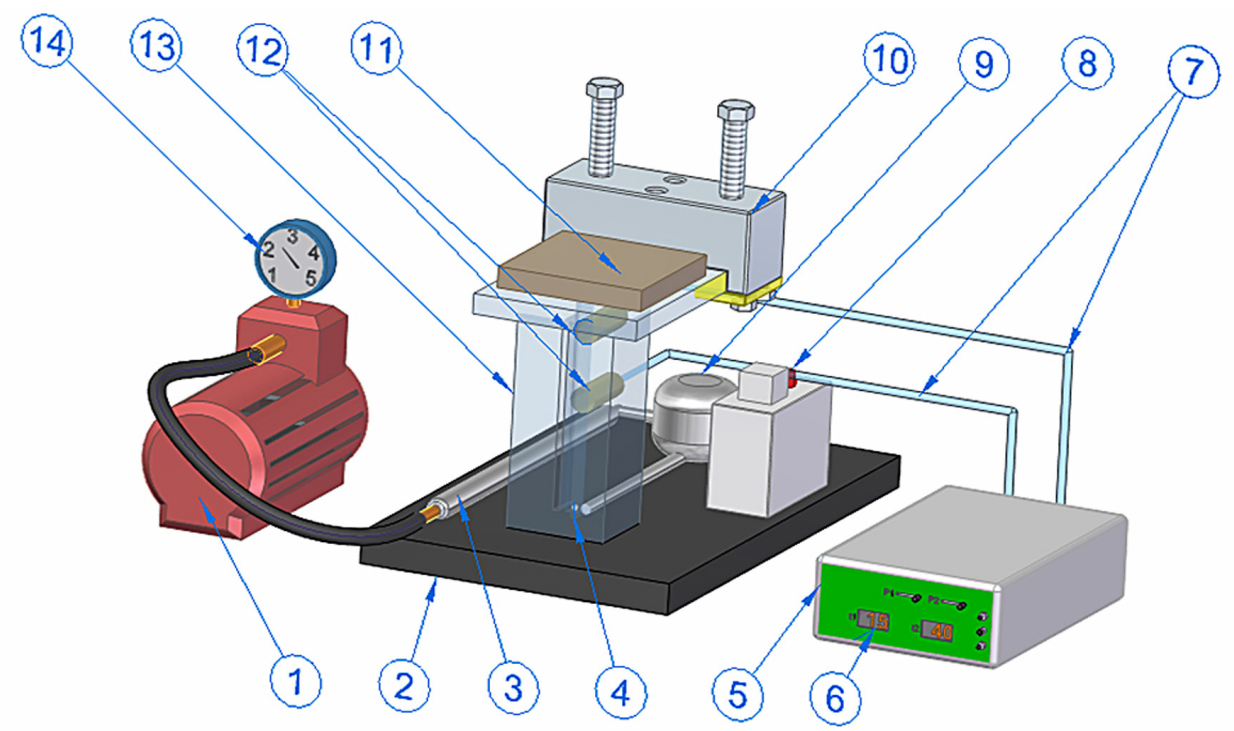

Fig. 5. Test stand for assessing the coefficient of restitution (described in the text) 
rigidly secured so as to allow the beads to impact the workpiece surface at a constant distance.

A ball bearing bead (4), also referred to as a shot medium, reaches a specified airspeed in the wind tunnel of the rack (13) thanks to a dose of compressed air. Compressed air under pressure $p$ is located in the cylinder (3). The compressed air is produced by a compressor (1) equipped with an indicator gauge (14). When pressed, the trigger (8) opens the solenoid valve (9) which conveys a dose of compressed air from the cylinder (3) into the wind tunnel of the rack (13), setting the bead (4) at the initial velocity $v$. The digital signal from the sensors (12) is transmitted over the wires (7) directly into the electronic control system (5) where two travel times of the shot medium (4) are conditioned and then displayed on the display (6).

\section{RESULTS}

Strong and non-linear dependence between roughness height and measured coefficient of restitution (Fig. 6) has been observed. Samples with low roughness $(\mathrm{Rz}=1.26 \mu \mathrm{m})$ were characterized with about $50 \%$ of the use of kinetic energy for plastic deformation. The rest of energy was turned back as kinetic energy of the rebound. The velocity of impact has a significant influence on the coefficient of restitution. The increase of velocity from $5 \mathrm{~m} / \mathrm{s}$ to $9 \mathrm{~m} / \mathrm{s}$ was connected with almost double decrease of the coefficient of restitution for low roughness samples. That indicates more intense plastic deformation at a higher velocity, which was confirmed by observational research (Fig. 9). The increase of surface roughness to Rz $=128.71 \mu \mathrm{m}$ results in further reduction of the coefficient of restitution value. This relationship can be interpreted as the effect of the inhibitory action of surface asperity.

The predicted relations between the surface roughness and the shape of the produced impression are presented in Figure 7. Bead is hitting the sample with velocity $\mathrm{v}_{1}$ which depends on air pressure p (Fig. 5). During the bead - samples structure contact, the complete restrain of initial velocity of bead occurs. In the last stage (Fig. 7c) the direction of the velocity vector is changing. Its value depends on the surface condition of the workpiece. The velocity $\mathrm{v}_{2}$ will always be greater for the sample with lower roughness and lower for the sample with a high parameter of roughness Rz.

Figure 8 presents the influence of the geometric structure on the character of the impression created. This paper is intended to clarify this relationship as the influence of the surface roughness onto the coefficient of restitution has not been researched yet. It can be observed that the increase of the roughness bead leads to the reduction of shot peening effectiveness. Too low kinetic energy of the bead causes only partial deformation of the surface asperity. With the increase of the initial velocity of bead, the depth on which plastic deformation increases. In other words, the effective shot peening of surfaces with increased roughness required increased ve-

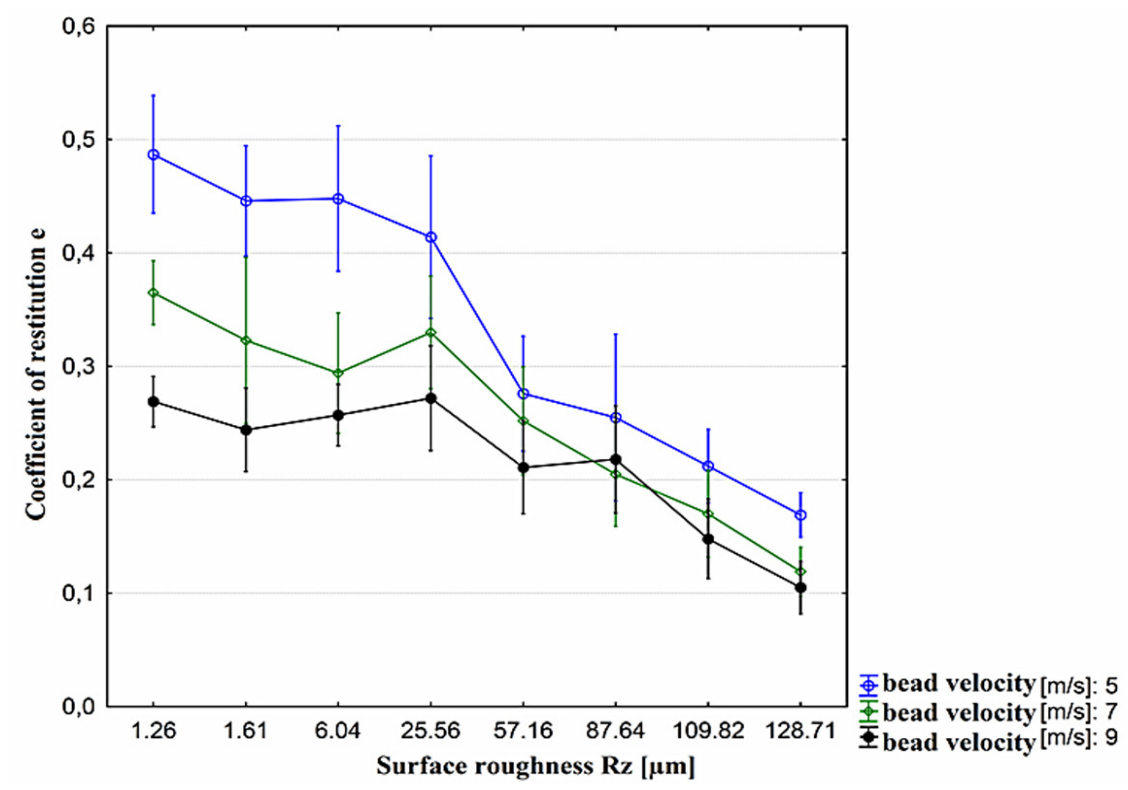

Fig. 6. The coefficient of restitution e in function of surface roughness Rz and velocity of hitting $\mathrm{v}$ bead with its diameter $\mathrm{d}=5.50 \mathrm{~mm}$ 

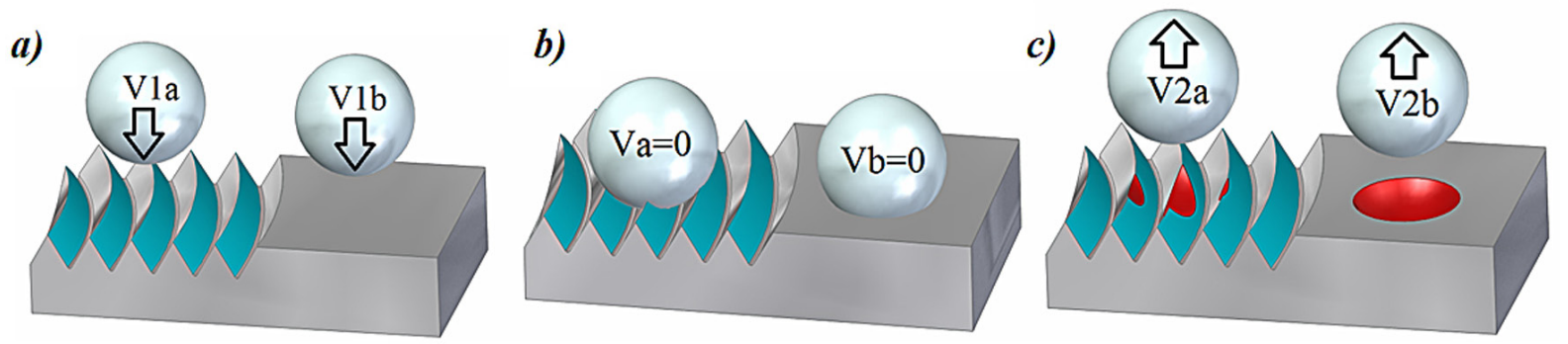

Fig. 7. Influence of surface condition on size and character of impression - structure bead-sample:

a) before hitting, b) at the moment of hitting, c) after hitting

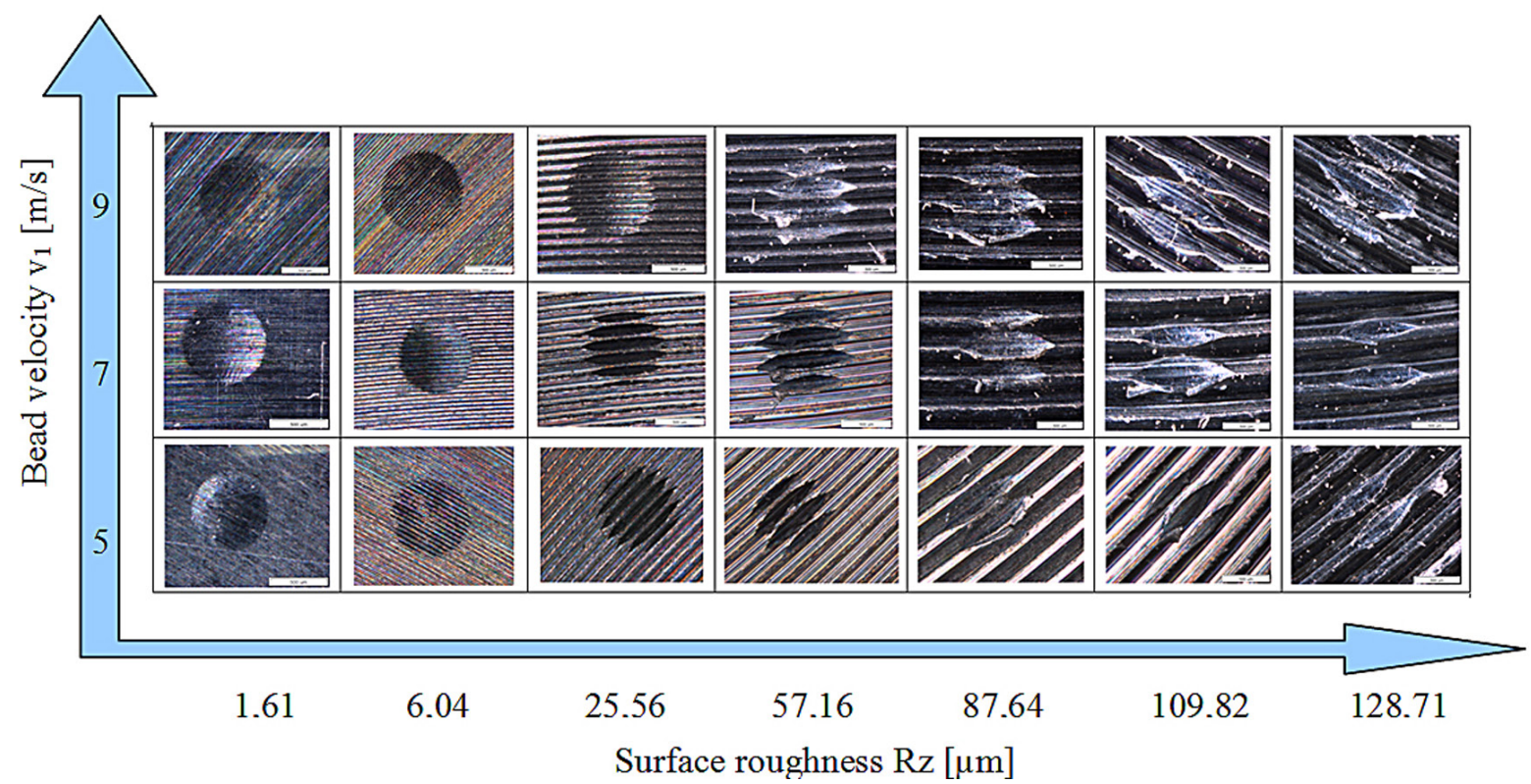

Fig. 8. The influence of the surface roughness and initial velocity of the bead on the shape and character of the impression formed as a result of the experiment, magn.: $x 40$
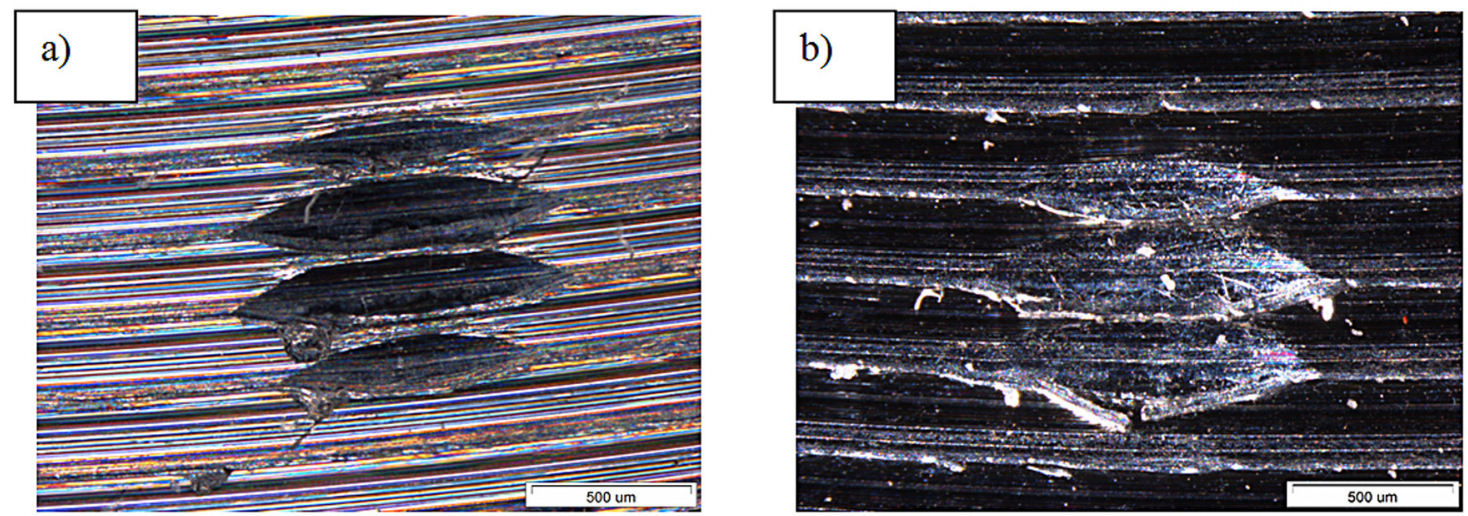

Fig. 9. High roughness surface after hitting by bead

locity of beads. It is connected with the initial treatment of roughness accompanied by friction and adhesion.

Under the microscope it can be observed that burrs are formed during the shot peening. A burr is formed as a result of the plastic shearing of high asperity after machining (Fig. 9b). In the case of a low level of roughness (about $1.61 \mu \mathrm{m}$ ), there is only crushing and rolling of the top of roughness. In the deformation zone, numerous cracks appear which later causes plastic cutting of the top of roughness (Fig. 9a). 


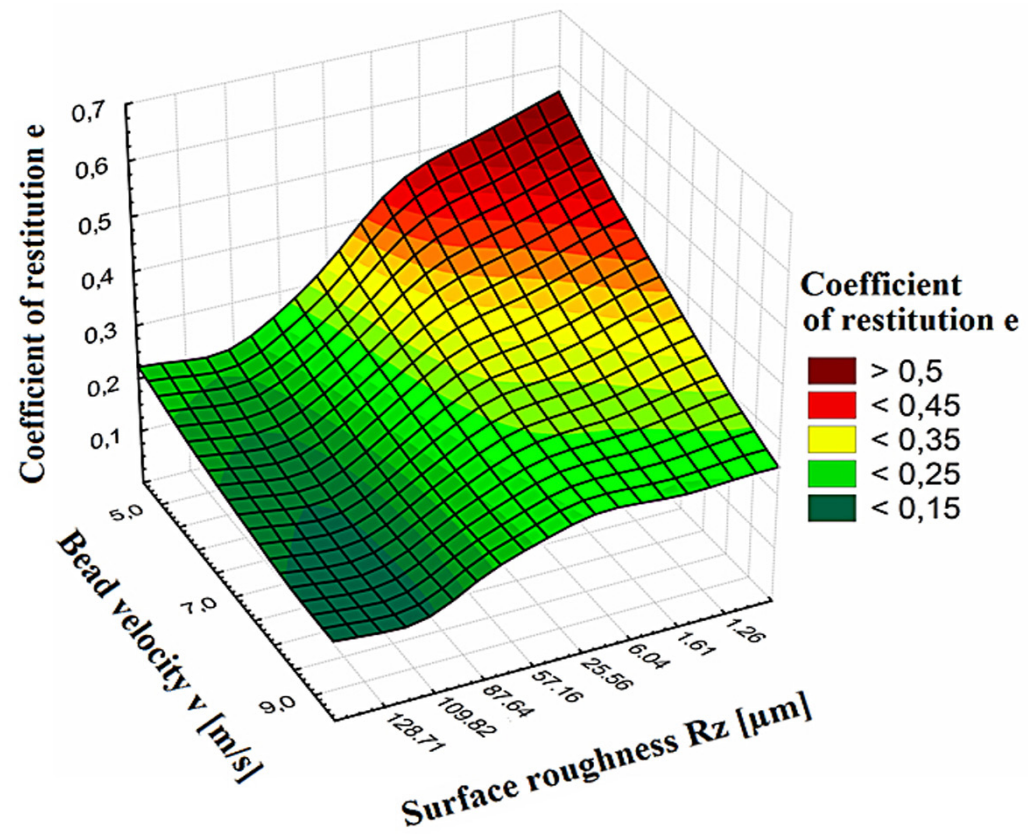

Fig. 10. The coefficient of restitution in function of surface roughness and bead velocity

\section{CONCLUSIONS}

The experiment allowed us to determine the effect of highness of surface roughness on the coefficient of restitution and the character of the impression formed. As a result, the following conclusions have been drawn:

1. The increase of bead velocity leads to the increase of diameter and depth of impression.

2. Together with the increase of roughness parameter $\mathrm{Rz}$, the coefficient of restitution is decreasing and the impression after the impact becomes irregular.

3. In the crumple zone of surface with high roughness, the process of "cutting" as a result of "pushing" irregularities take place and numerous of cracks appear on their surface.

4. Much greater quantities of energy should be used to achieve the effect of homogeneous shot peening of the surface of high roughness Rz.

5. Shot peening of higher roughness surface should be conducted in two stages: initially treating with high hitting energy, secondly and finishing with lower intensity of treatment.

\section{REFERENCES}

1. Burakowski T., Wierzchoń T., Inżynieria powierzchni metali. WNT, Warszawa 1995, 47-164.
2. Bhuvaraghan B., Sivakumar M.S., Prakash O., Overview of the effects of shot peening on plastic strain. In: W.U. Oster (Ed.) Work Hardening and Residual Stresses, Computational Materials. Nova Science Publishers, 2009, 49-117.

3. Cammett J., Shot peening getting it righ. The Shot Peener, 2, 2007, 8-14.

4. Kukiełka L., Kułakowska A., Problematyka przygotowania powierzchni $\mathrm{w}$ procesie toczenia $\mathrm{w}$ aspekcie jakości technologicznej wyrobu nagniatanego, PAK, 54(7), 2008, 421-424.

5. Kukiełka L., Kułakowska A., Patyk R., Problematyka kształtowania jakości technologicznej części $\mathrm{w}$ procesie nagniatania powierzchniowego, PAK, 54(4), 2008, 196-199.

6. Higounenc O., Correlation of shot peening parameters to surface characteristic. ICSP 9, 2005, $28-35$.

7. Osiński Z., Mechanika ogólna. PWN, Warszawa 1997, 388-404.

8. Schwager T., Poschel T., Coefficient of restitution and linear-dashpot model revisited. Granular Matter, 9, 2007, 465-469.

9. Antonyuk S., Heinrich S., Tomas J., Deen N., Buijtenen M., Kuipers J., Energy absorption during compression and impact of dry elastic-plastic spherical granules. Granular Matter, 12, 2010, $15-47$.

10. Łunarski J., Cisek Z., Badania współczynnika restytucji w procesie kulowania stopów tytanu. Zesz. Nauk. Politechniki Rzeszowskiej, 83, 1991. 